\title{
Una edición crítica del Chronicon mundi de Lucas de Tuy
}

\section{Emma Falque}

\section{Citer ce document / Cite this document :}

Falque Emma. Una edición crítica del Chronicon mundi de Lucas de Tuy. In: Cahiers de linguistique et de civilisation hispaniques médiévales. N²4, 2001. pp. 219-233.

doi : $10.3406 /$ cehm.2001.1177

http://www.persee.fr/doc/cehm_0396-9045_2001_num_24_1_1177

Document généré le 21/10/2015 


\section{Una edición crítica del Chronicon mundi de Lucas de Tuy}

\section{UNA LARGA ESPERA}

$\mathrm{Al}$ aceptar la amable invitación que en su momento me hizo el prof. Patrick Henriet para participar en este coloquio, dí como título « Una edición... », porque no creo que haya ediciones críticas definitivas. Si algo me parece importante del movimiento a que ha dado lugar la obra de Bernard Cerquiglini, es precisamente la importancia que tiene cada uno de los testimonios que se nos conservan de un texto, dado el hecho de que siempre hay que contar con una aventura interpretativa por parte de los copistas, pues éstos realizan su trabajo y no son sólo depositarios de errores para que, a través de ellos los editores podamos hacer el nuestro, organizando los manuscritos en que se nos conserva una obra. ¿Cómo no voy a pedir el mismo trato, mantener la misma actitud, afrontar los mismos riesgos y hasta moverme en la misma provisionalidad en mi labor como editora?

Con toda humildad, a la vez que con el mayor placer que se deriva de la tarea cumplida vengo a presentar una - y ojalá no sea la última edición crítica del Chronicon mundi de Lucas de Tuy.

Lo que les presento aquí son las 350 páginas del texto, que, Deo uolente, estará en breve en las prensas de Brepols. Simplemente para decir esto es para lo que acepté participar en este coloquio, pues son tantas las ocasiones en las que mis colegas me han preguntado cómo va mi edición con el consiguiente desaliento mío - y tantos los cambios que he tenido que ir haciendo a lo largo de mi tarea, que me parece razonable en el momento final darles cuenta de ello, por si aún estoy a tiempo, con sus sugerencias, de poder librarme de algunos inevitables errores.

No puedo decir, por otro lado, que no haya habido intentos desde la edición del Padre Mariana hasta la mía de proporcionar un texto crítico 
del Chronicon mundi. Esto, que a veces me ha confirmado en la oportunidad de realizar este trabajo, me ha llegado a preocupar muchas otras, al pensar que el mío podía convertirse en un intento más que no llegara a buen término. El hecho es que hasta ahora la única edición con la que contábamos era la de Mariana, publicada por el también jesuita A. Schott, que tiene el indudable mérito de ser la primera y de haber sido durante siglos - desde principios del XVII - la que ha posibilitado la lectura del Chronicon mundi a diferentes generaciones de historiadores y filólogos interesados por don Lucas.

A. Schott no da noticias sobre esta edición de Mariana y se limita a decir al final de la dedicatoria del tomo IV de la Hispania illustrata que el Chronicon mundi no había sido impreso anteriormente (... typis antea numquam euulgatum), de ahí que todavía hoy sea frecuente encontrar en estudios sobre el Tudense referencias a «la edición de Schott», cuando éste se limitó a publicar el texto, cuyo editor propiamente dicho, en el sentido que tiene el término en crítica textual, fue Juan de Mariana. Éste, según nos informa Cirot, contó con cinco manuscritos y mandó colacionar en algunos pasajes el manuscrito salmantino, aun a sabiendas lo señalaba en su prefacio a la edición del De altera uita - de que existían otros. Al no proporcionar aparato crítico y no decir explícitamente en el prólogo a la edición ni en otras obras ni en su correspondencia los códices a que acudió, no resulta sencillo saber los manuscritos concretos que empleó en su trabajo, ni el sistema de elección en sus lecturas de variantes.

Lo que es evidente es que, con todos sus méritos, la edición de Mariana dejaba descontentos por igual a filólogos e historiadores. Por ello B. F. Reilly ${ }^{1}$ lo exponía con claridad y precisaba que se necesitaba disponer de una nueva edición de Lucas de Tuy porque podía ofrecer la base para nuestro conocimiento sobre la historia y la literatura en los siglos XI y XII.

Esto explica que haya habido algunos importantes intentos de proporcionar una edición crítica de esta obra, que desgraciadamente no llegaron a buen puerto. Me refiero a los de G. Cirot, J. Puyol, B. Sánchez Alonso y L. Vázquez de Parga.

Del proyecto de Cirot da cuenta él mismo en su monografía sobre el padre Mariana ${ }^{2}$, donde nos informa que ha estudiado seis manuscritos del Chronicon mundi, entre ellos dos del siglo XIII, el conservado en Salamanca y el que estuvo en Toledo, además de tres de la Biblioteca

1. Bernard F. REILLY, «Sources of the Fourth Book of Lucas of Tuy's Chronicon mundi », Classical Folia, 30 (2), 1976, p. 127-137, p. 137.

2. Georges CIROT, Mariana historien, Paris, 1905, p. 75 nota 2. 
Nacional de los siglos XIV, XV y XVI y uno del XVI de Salamanca ${ }^{3}$, aunque confiesa que no ha podido verificar su colación in situ, tarea que reservaba para el momento en que pudiera preparar una nueva edición de Lucas de Tuy.

En España, el primer intento de llevar a cabo la edición crítica corrió a cargo de don Julio Puyol, académico de la Real Academia de la Historia, bajo cuyos auspicios pensaba realizar el trabajo, del que sólo llegó a ver la luz un artículo preparatorio ${ }^{4}$. Si bien dificultades de distinto signo impidieron a Puyol finalizar el proyecto, éstas no fueron obstáculo para que no pudiera publicar, al menos, la traducción castellana de la crónica que apareció en 1926, « conforme - según consta en el prólogo - al códice más antiguo de la misma $»^{5}$ que poseía la Academia. La traducción castellana de Puyol cubrió un hueco, pues a falta de una edición reciente ha permitido a muchos estudiosos acercarse al texto de Lucas de Tuy.

Años más tarde, en 1947, B. Sánchez Alonso en su Historia de la historiografia española al referirse al estudio de las fuentes de esta obra de Lucas de Tuy dice textualmente: « en ello he trabajado, con vistas a una edición crítica de la crónica... $»^{6}$. Desconocemos las causas de por qué esta intención del historiador español no llegó a hacerse realidad.

El proyecto más reciente de realizar una edición crítica fue el de don Luis Vázquez de Parga, también académico de la Real Academia de la Historia, quien emprendió la tarea de una nueva edición, pero no llegó a publicarla. Con él intenté colaborar hace ya algún tiempo, pero fue una colaboración que desgraciadamente no pudo llevarse a cabo. Por lo que, llevada quizás de un entusiasmo excesivo, inicié sola la edición crítica del Chronicon mundi para el Corpus Christianorum.

A todo ello hay que añadir no ya un proyecto, sino una edición inédita: la presentada en 1997 como tesis doctoral por la mejicana doña Olga Valdés, realizada bajo la dirección de la Dra Carmen Codoñer, que no ha llegado a publicarse, ni total ni parcialmente, y que yo he creido oportuno no consultar, al estar trabajando en mi edición por entonces.

3. Los manuscritos estudiados por Cirot eran los siguientes (incluyo las signaturas y las siglas que utilizo tanto en este trabajo como en otros y que mantendré en mi edición) : $S$ (Salamanca, Biblioteca Universitaria 2248, s. XIII), $T$ (Madrid, Biblioteca Nacional 10442, olim Toletanus 27-28, s. XIII), M. (Madrid, Biblioteca Nacional 4338, s. XIV), A (Madrid, Biblioteca Nacional 1534, s. XV), $\mathcal{f}$ (Madrid, Biblioteca Nacional 898, s. XVI), G (Salamanca, Biblioteca Universitaria 1791, s. XVI).

4. J. PUYOL, «Antecedentes para una nueva edición de la crónica de Don Lucas de Tuy », AH 69, 1916, p. 21-32.

5. J. PUYOL (ed.), Crónica de España por Lucas, obispo de Tuy, Madrid, 1926, p. V.

6. B. SÁNCHEZ ALONSO, Historia de la historiografia española, I, Madrid, 1947, p. 127 nota 57. 


\section{EL RIESGO DE QUE APAREZGAN NUEVOS TESTIMONIOS}

Cuando, hace ahora dos años, nos reuníamos también en París algunos de los que nos encontramos hoy aquí, junto con otros profesores, fundamentalmente franceses y españoles, en un seminario dirigido por el prof. Georges Martin, presenté entonces un trabajo, en el que intentaba ofrecer una visión de conjunto, desde un punto de vista fundamentalmente filológico, de la transmisión manuscrita del Chronicon mundi de Lucas de Tuy ${ }^{7}$.

En aquel momento contaba con 17 manuscritos, que mostré agrupándolos en distintas ramas, proponiendo un stemma codicum de los testimonios conservados de esta obra del Tudense. Pero ya entonces apunté que acababa de tener noticias de la existencia en Barcelona de otro testimonio de esta obra: el ms. 1003 de la Biblioteca de Catalunya, que aún no había podido consultar.

Poco después de este coloquio celebrado en París pude colacionar este códice, al que denominé $B$ y que era de finales del siglo XIII o principios del siglo XIV, sobre el que presenté una comunicación en un congreso celebrado en Tortosa en abril de $1998^{8}$. Este manuscrito tenía la peculiaridad de ser acéfalo y ápodo, pues se ha perdido el comienzo del prólogo de la obra y termina en la página 93 de la edición de Mariana, que recordemos tiene 116 páginas. Faltaba, pues, una quinta parte del texto, ya que al final deben haberse perdido unos cuarenta folios; no obstante, aun estando incompleto en la actualidad, es un códice que debe ser muy tenido en cuenta por quien se acerque a la obra del Tudense o pretenda acometer la tarea de realizar una edición crítica de la obra, pues resulta ser uno de los testimonios más antiguos de la misma.

No hace mucho me llegaba otra noticia, gracias a la amabilidad del Dr José Carlos Martín, que para un editor a punto de terminar una edición crítica podía suponer una auténtica catástrofe: había otro manuscrito de Lucas de Tuy en Nueva York, en la biblioteca de la Hispanic Society, que no aparecía en la relación ofrecida en el Index... de M. C. Díaz y Díaz y que había pasado desapercibido hasta entonces a pesar de estar incluido en el catálogo de Ch. B. Faulhaber ${ }^{9}$. Se trataba de un códice del siglo XVI (a. 1582) copiado o procedente precisamente

7. Emma FALQUE, «Hacia una organización textual de los manuscritos del Chronicon mundi de Lucas de Tuy », Cahiers de linguistique hispanique médiévale, 23, 2000, p. 87-99.

8. Emma FALQUE, «Los testimonios manuscritos de Lucas de Tuy de la Biblioteca de Catalunya », en L. FERRÈRES (ed.), XIII Simposi d'estudis clàssics (en prensa).

9. Hispanic Society of America, HC 385/280. Cf. Ch. B. FAULHABER, Medieval Manuscripts in the Library of the Hispanic Society of America: Religious, Legal, Scientific, Historical and Literary Manuscripts, Nueva York, 1983, n 467, p. 459-461. 
de Sevilla, que hube de estudiar e incluir en el stemma codicum que ya había elaborado.

Este nuevo testimonio conservado en la actualidad en Nueva York es un códice del siglo XVI que contiene básicamente el Chronicon mundi, pero que puede haber pasado por manuscrito de San Isidoro, puesto que en las hojas de guarda hay una relación de obras del santo hispalense que se encontraban en distintas bibliotecas de Sevilla ${ }^{10}$. Ya que procede de esta ciudad, si es que no fue copiado allí, en un principio consideré que podía estar relacionado con uno de los manuscritos de la Biblioteca Colombina, también del siglo XVI. Me equivoqué totalmente. Un editor debe saber que estas coincidencias que podríamos llamar de carácter geográfico no siempre tienen correspondencia en las relaciones, a veces complejas, que entrelazan unos testimonios con otros en el conjunto de una transmisión manuscrita.

Prueba de que el método lachmaniano sigue siendo válido es que el stemma que presenté hace dos años - tan provisional como casi todo lo que hacemos los filólogos - ha resistido los embates de la necesidad de tener que incluir estos dos nuevos testimonios, a los que me he referido.

El primero, el de Barcelona, no puede ser encuadrado en ninguna de las ramas que había establecido: la de $S\left(S_{S} V F\right)$ y la de $T(T P L \mathcal{F} K)$, a las que habría que añadir, por una parte, un grupo de manuscritos que tienen algunas características comunes $(M A C E G H h)$, que posiblemente deriven de $M$, el códice más antiguo de este grupo, y, por otra, el más antiguo de León $(I)$, que constituye un caso especial y aislado. Pero ese códice de la Biblioteca de Catalunya está más relacionado con $S$ que con ITM. Así parece demostrarlo el que ambos $(S B)$ se opongan en varias ocasiones a estos últimos (ITM) ofreciendo pasajes que omiten éstos y omitiendo otros transmitidos por los demás. Derivaría, pues, junto con $S$ de un mismo subarquetipo.

He aquí algunos ejemplos:

a. « anni quos debebat pati Nabuchodonosor in septem » : SB, om. ITM Mar. (Mariana: p. 19, 1)

b. « Hic fecit uineam auream in qua erant diuersi generis gemme pro racemis pendentes » : ITM Mar., om. SB. (Mariana: p. 21, 16-17)

c. « Sirie et Babilonie et superioribus locis que sunt ad orientem »: $S B$ Mar., om. ITM (Mariana: p. 22, 27-28)

d. « hospitale pauperum in Iherusalem et muros fortes in eo instituit » : SB, om. ITM (Mariana: p. 25, 5)

10. Con el título siguiente: Memoria de los libros de San Isidro que yo el Licenciado Ponce he buscado en todas las librerias desta ciudad de Sevilla por mandado del ArÇobispo mi señor, al final de la cual se refiere a este manuscrito como Historia en pergamino [...] hecha por Sant Isidro hasta su tiempo a quien sigue sancto Illefonso Arçobispo de Toledo hasta el suyo y acabado por Don Lucas de Tui, obispo de Tui. 
En cuanto al segundo, al que llamaré $Y$, podemos situarlo bien en una de las dos ramas que establecí: la del códice más antiguo de Salamanca y sus derivados $(S s V F)$. Ya el comienzo del prólogo del Tudense a la Crónica de Isidoro ("Beatitudo potentiae temporalis tunc in uero esse disponitur...») y el del prólogo del propio Isidoro («Breuem temporum annotationem per generationes... ») nos permite relacionarlo con la familia de $S$, pues sólo los relacionados con $S$ nos han transmitido el comienzo de ambos prólogos.

Pero además el manuscrito de Nueva York $(Y)$ conserva dos de las grandes omisiones que caracterizan a esta familia. Una de ellas es la famosa anécdota de la invención del vidrio irrompible, que el Tudense sitúa en época de Tiberio y que encontramos también en el Satiricón (Sat. 51) y posteriormente en la Etimologías de San Isidoro (XVI, 16, 6) :

« Cuius tempore Lucillus quidam excogitauit... auri et argenti uilesceret pretium » : om. SsVFY (in Y ad marg. addito) (Mariana: p. 31, 18-25).

Hay que señalar, pues, que representa un caso más de contaminatio; obviamente el copista tenía dos manuscritos diferentes delante o cotejó luego su copia con otro. No es éste el único caso de contaminatio en la transmisión manuscrita de esta obra del Tudense, pues se dan varios casos más entre las diferentes ramas, lo cual complica siempre el establecimiento de la relación de los distintos testimonios entre sí.

Por tanto, en este momento contamos con 19 manuscritos que nos han transmitido el Chronicon mundi, de los que sólo dos están incompletos: uno de los conservados en la Universidad de Salamanca que contiene el libro I, y uno de los de la Biblioteca Colombina de Sevilla, que únicamente nos transmite los libros III y IV. Se trata, pues, de una tradición manuscrita relativamente amplia e importante si la comparamos con la de otras obras medievales, y, desde luego, con la de otros trabajos de Lucas de Tuy. Sin llegar al extremo del De altera uita, obra de la que se conserva un único manuscrito, que además es muy tardío (s. XVII) y que planteará a la hora de acometer la tarea de la edición crítica todos los problemas del codex unicus - que es una de las situaciones quizás más difíciles ante la que puede encontrarse un filólogo - disponemos de un mayor número de manuscritos del Chronicon mundi que de los Miracula, conservados sólo en cuatro manuscritos, cuya menor difusión - me refiero tanto al pequeño número de códices como a que no haya sido editada nunca en su totalidad - quizás se deba, a pesar del indudable interés que podía tener, a que pronto apareció una traducción castellana ${ }^{11}$. Para la edición latina, espero que podamos contar en breve con la edición crítica de los Miracula que prepara el prof. Henriet. 
Por otra parte, aunque recordemos el viejo principio enunciado por Lachmann de recentiores non deteriores, atendible siempre en filología, es evidente que la transmisión manuscrita del Chronicon mundi es realmente importante y sorprendentemente se nos han conservado testimonios muy antiguos, cercanos al momento en que el autor redactó la obra, a diferencia de lo que suele ocurrir con las obras medievales. No olvidemos que de un texto cuya redacción podemos situar hacia 1240, conservamos tres códices del siglo XIII (SIT), uno que podríamos fechar a finales del XIII o principios del XIV $(B)$, tres del XIV (MPS) y cuatro del $\mathrm{XV}(V C A L)$, dejando a un lado los posteriores, de los siglos XVI y XVII.

\section{¿QUé se ogulta en un aparato Grítigo?}

Para una neolachmaniana convencida, los testimonios existentes de un texto como el de nuestra crónica, tienen un fin claro: organizar por medio de ellos la relación entre manuscritos, para poder hacer después, una propuesta razonable de arquetipo. Pero quien siendo neolachmaniana, convencida del valor de esta técnica para la edición crítica de un texto, no se complace en vivir en el dogma, entiende también que, tal y como han visto algunos filólogos actuales ${ }^{12}$, los editores no deberían reducir su actuación a reconstruir un texto, excluyendo de él los errores y cambios que ha experimentado a lo largo de su historia. La actuación de los copistas no es sólo pasiva, sino que a menudo supone una alteración consciente de un texto, que en las obras históricas medievales se tiene, además, como un material susceptible de ser mejorado por los demás ${ }^{13}$.

No podemos dejar de contar, por lo tanto, en el largo proceso de transmisión de los textos clásicos y de los medievales, con la intervención decidida de los copistas. Hay a este respecto un pasaje muy interesante en el Chronicon mundi en el que los manuscritos más antiguos que nos han transmitido la obra difieren, pues hay tres que coinciden en la omisión de un párrafo de la misma manera. La omisión no carece de interés, ya que está relacionada ni más ni menos con la primacía de Toledo. Se encuentra al final del libro III, en la continuación de la obra de Julián de Toledo y se refiere al rey godo Ervigio ${ }^{14}$, de quien se cuenta

12. He tratado algunos aspectos generales de la edición de textos latinos en un trabajo reciente, $f f$. Emma FALQUE, "Edición de textos y new philology », in: X Congreso de la SEEC (en prensa).

13. El arcipreste de Hita, por ejemplo, anima a sus lectores a ir cambiando a su gusto el Libro de buen amor.

14. Véase el libro, ya clásico, de Thompson, traducido al español: E. A. THOMPSON, Los godos en España, Madrid, 1971, (Ervigio: p. 264-276) y para la España visigoda:J. ORLANDIS, 
que celebró numerosos concilios en Toledo y entre otras disposiciones legales estableció que ningún arzobispo en España estuviera sometido a ningún primado, excepto el de Roma. El pasaje es el siguiente (Mariana: p. 69, 2-7):

Hic sinoda multa cum episcopis apud Toletum egit; [...] Romani Pontificis assensu statuit, ut nullus archiepiscopus Ispaniarum subderetur alicui primati nisi Romano tantum.

El texto fue editado así, con algunas variantes, por Mariana ${ }^{15}$; sin embargo, algunos manuscritos omiten este mandato de que ningún arzobispo hispano estuviera sometido a primado alguno excepto al de Roma. Lógicamente entre estos códices se encuentra el del siglo XIII que estuvo en Toledo y se conserva en la actualidad en la Biblioteca Nacional de Madrid ( $T=$ BN 10442) y esta misma omisión aparece recogida por el más antiguo de los de la Real Colegiata de San Isidoro de León $(I=$ San Isidoro 20) y por uno del siglo XIV también de la Biblioteca Nacional $(M=$ BN 4338). Desde un punto de vista de transmisión textual esto es perfectamente explicable, ya que se trata de manuscritos que, tal como creo haber demostrado al abordar el stemma, están relacionados entre sí. En su día supuse un subarquetipo del que derivaría una familia, en la que habría que incluir $I, T$ y $M$. Podría ciertamente este subarquetipo estar relacionado con Toledo y ello explicaría el interés por omitir esta disposición; la otra posibilidad, que todos los códices dependieran directamente de $T$, habría de excluirse, pues éste presenta errores propios que, como también expuse en su momento, dan origen a una familia (TPLK) pero que no aparecen ni en $I$ ni en $M$.

Lo que me interesa demostrar con este ejemplo tomado de la edición es que no puede ser casual que los copistas - o mejor, el copista de ese manuscrito perdido, que he supuesto como arquetipo del que derivarían todos éstos - hayan omitido precisamente este párrafo que choca frontalmente contra los intereses de la iglesia toledana y la primacía que correspondía al arzobispado de Toledo. Hay aquí una decidida intervención de los copistas - al modificar de manera sustancial el texto que transmiten - que no puede ser tomada como una simple omisión, del

Historia de España. Época visigoda (409-711), $1^{\text {a }}$ reimpr., Madrid, 1999. Como obra muy reciente y de carácter más general, véase R. MUSSOT-GOULARD, Les Goths, Biarritz, 1999.

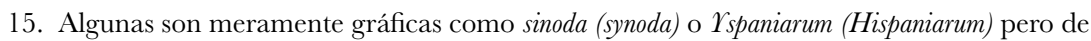
mayor interés es que frente al tantum de mi edición que recalca la disposición anterior («... alicui primati nisi Romano tantum ») en la edición de Mariana encontramos tamen, que además se incorpora a la frase siguiente: « ... primati nisi Romano. Tamen pius et modestus...» (en mi edición: « ... primati nisi Romano tantum. Pius et modestus...»). 
tipo de otras muchas que podrían aducirse, basada en hechos mecánicos, como por ejemplo las causadas por haplografia o por saltos entre palabras iguales, tan numerosas siempre en todos los códices. En este caso se esconde una fuerte razón ideológica detrás de una omisión, que no es nada inocente, pues el texto completo suponía un auténtico grito de rebeldía contra la primacía toledana.

También relacionado directamente con la primacía de Toledo hay otro pasaje, sobre el que ya ha llamado la atención el prof. Linehan ${ }^{16}$. Está en la página 56, 48-49 de la edición de Mariana en la División de Wamba que nos ha transmitido el Tudense. El texto que presento en mi edición ${ }^{17}$ es el siguiente:

Rex Bamba, ut supra scriptum est, diuisionibus episcopatuum confirmatis ceteras imperii sui sedes diuisit, sic dicens: Toletum metropolis, regia sedes, inter ceteros Yspanie, quandiu huic sancto cetui [i.e. coetui] placuerit, metropolitanos teneat primaciam.

También aquí se da una diferencia, y sustancial, entre los diferentes testimonios: un grupo de manuscritos, entre los que no podía faltar el de Toledo (ITM), omite esa incómoda cláusula para la sede toledana. Me refiero al « quandiu huic sancto cetui » con lo que los manejos de un copista convierten el texto en una ratificación del derecho de Toledo a ejercer la primacía: «Toletum metropolis, regia sedes, inter ceteros Yspanie metropolitanos teneat primaciam. » (ITM)

Quien copia hace más que transcribir: interviene en el texto y su intervención, según hemos visto, puede modificar completamente el significado de un pasaje. Aunque, a veces, no de tanta trascendencia como la que supone discutir los privilegios de la sede toledana. En la edición del Padre Mariana tenemos un ejemplo de esto: es el «puritanismo » del editor - si se me permite el término - el que le lleva a modificar lo que tenía delante, a pesar de la total unanimidad de los manuscritos en este punto ${ }^{18}$. Cuenta nuestro autor que doña Urraca, la

16. Peter LINEHAN, History and the Historians of Medieval Spain, Oxford, 1993, p. 379.

17. Este texto sólo difiere de la edición de Mariana, además de en la grafía, pues la de mi edición recoge la de los manuscritos, en que aquél da regis sedes en lugar de regia sedes, que podría ser errata, y diuisionibus Epantuum confirmatis, con un Epantuum que parece nombre propio imposible de identificar y que no es más que abreviatura de episcopatuum.

18. Llevada por la curiosidad de saber si algún copista había modificado este pasaje lo he colacionado en todos los manuscritos conservados. Si exceptuamos los casos de $B$, en el que faltan los últimos folios y por tanto no nos ha transmitido estos capítulos finales, y de $S$, que sólo contiene el libro I, absolutamente todos los testimonios ofrecen la misma lectura: «... spretis carnalibus copulis periturique mariti amplexibus ». No hay correcciones y sólo $M$. añade al margen, como suele hacer, un resumen, que facilita quizás la búsqueda de determinados pasajes o la lectura del texto (« regina Urraca sub laicali habitu monachali observatione intrinssicus (sic) Christo adherebat »). 
hermana mayor del rey Alfonso VI, rechazando un posible matrimonio, aunque exteriormente vestida con ropas laicas, observaba en su interior la regla monástica y decidió consagrarse a Cristo como único esposo. Para expresar el rechazo de doña Urraca el texto es suficientemente expresivo: «rechazadas las uniones carnales y los abrazos de un marido que habría de morir [...] se consagró a Cristo como auténtico esposo », que es lo que mantengo en mi edición:

... spretis carnalibus copulis periturique mariti amplexibus [...] Christo uero sponso adhesit. (Mariana: p. 99)

El padre Mariana, pudibundo, elimina el término copula que si en latín puede tener un significado más amplio de «vínculo, unión », tiene un sentido clarísimo al ir unido al adjetivo carnalis y estar relacionado con amplexibus, los abrazos de ese hipotético marido rechazado por doña Urraca, y transforma copulis en copiis, velando un texto que era muy claro. Son hechos de distinto tipo, coincidentes todos en señalar que una edición crítica permite, a través de sus variantes, mostrar también la participación de los lectores - los copistas de una manera particular en la interpretación de un texto. El nuestro, como todos, no se crea en el vacío.

\section{MÁs Allá DEL TEXTo}

Quien pasa unos cuantos años colacionando manuscritos, pendiente de las pequeñas diferencias - o grandes - que se dan entre ellos, a veces levanta por un momento los ojos de las variantes y se para a pensar en la función del texto que tiene delante; porque no es lo mismo que lo que transcribe tenga que ver con los ocios de un clérigo o se trate de una obra escolar o estemos a punto de adentrarnos por un texto construido para convencer o anonadar a los discrepantes de una idea. Tantas preguntas como éstas asaltan a cada paso al filólogo, que desearía muchas veces cerrar las puertas de su taller y dedicarse al estudio de la historia: la pasión por el texto no termina en sí misma, pues abre las puertas de la historia que se esconde tras la letra. Aunque, con respecto a esto, el filólogo va haciéndose más preguntas que respuestas es capaz de darles.

De entre tantas preguntas sin respuesta, una me ha asaltado varias veces a lo largo de mi trabajo sobre este texto: los hispanistas sitúan en el siglo XIII el momento en que el castellano hace desaparecer el leonés escrito, hacia la época en que Fernando III el Santo reinaba en Castilla y León y antes de que los textos romances, salidos de la cancillería regia en tiempos de Alfonso X, muestren sin ningún lugar a dudas no sólo el 
vigor del castellano, sino también el prestigio de la norma castellana nueva $\mathrm{o}$, si se prefiere, toledana ${ }^{19}$.

En esta situación en que el castellano adquiere en la corte real la condición de servir de vehículo a la labor historiográfica nos encontramos con que un modesto intelectual - en el sentido con el que Jacques Le Goff se ha atrevido a emplear este término en el medievo - Lucas de Tuy trama una interpretación histórica de un reino - León y Castilla desde una perspectiva orgullosamente leonesa; y lo hace mientras es canónigo de San Isidoro, pues cesa en su empeño una vez nombrado obispo de Tuy y cuando su persona tiene ya una cierta relevancia. Para un buen intelectual - lejano aún del pulcro humanista - todo sirve, incluso inventarse una fuente, si es necesario, en una obra polémica tras la que se trata de ir contra la preeminencia de la sede toledana frente a todas las demás; o si se prefiere, de la nueva Castilla, Castilla al fin, frente a León.

Se trata, en realidad, de dirimir una preeminencia que termina, de hecho, siendo política; y se hace en los círculos intelectuales del momento, es decir los eclesiásticos y, dentro de éstos, el del clero regular en el que el eje del poder parte del obispo ${ }^{20}$, entre el que se trata de dirimir una preeminencia que termina, de hecho, siendo política. A este respecto Lucas de Tuy se enfrenta con los posibles escritores, posteriores a él, que defiendan la causa de Toledo, y actúa con astucia y hasta con maldad: tanta como para hacer caer a Jiménez de Rada en la trampa de una fuente inventada, sin otro fin que el de apoyar en ella el « leonesismo » que confirma el texto ${ }^{21}$.

Estamos ante los últimos pasos de una explicación histórica de los hechos que comienza en el Tudense, desarrollada en los círculos eclesiásticos medievales: una obra en la que la iglesia - es decir, los intelectuales - aportan al poder la justificación de sus objetivos.

¿Cómo se puede explicar la ruptura que supone el paso de una obra

19. J. GUTTIÉREZ GUADRADO y J. A. PASGUAL, « De cómo el castellano se convirtió en español », in : A. GARCÍA SIMÓN (ed.), Historia de una cultura. La singularidad de Castilla, Valladolid, 1995, p. 135-171.

20. Pueden verse aspectos relacionados con el poder de los obispos y las órdenes mendicantes en la España del siglo XIII en el reciente estudio, documentado y sugerente, de P. LINEHAN, Les Dames de Zamora. Secrets, stupre et pouvoirs dans l'Église espagnole du XIII siècle, Paris, 1998.

21. El comienzo del libro tercero del Chronicon mundi, atribuido falsamente a San Ildefonso, arzobispo de Toledo, que ya demostró en el siglo XVIJuan Bautista Pérez que era una obra espúrea. Para este "Pseudo-Ildefonso », véase Peter LINEHAN, History and the Historians, p. 358, 363 nota 51 y p. 376-377; Id., « On further thought: Lucas of Tuy, Rodrigo of Toledo and the Alfonsine histories ", Anuario de estudios medievales, 27 (1), 1997, p. 415-436, p. 426; Id., « Reflexiones sobre historiografia e historia », Cahiers de linguistique hispanique médiévale, 23, 2000, p. 101-111, p. 103. 
como la de Jiménez de Rada en latín a la de Alfonso X en romance? Los deseos de divulgación a que acuden los hispanistas no me parecen de suficiente entidad, cuando ni el número de copias que podía hacerse de un texto que podía hacerse de un texto era elevado ni elevado era tampoco el número de las personas capaces de leerlas. La primera gran fractura del latín como lengua de cultura, dando paso al romance de la Crónica general y de la General Estoria, no puede entenderse sino en el contexto de una monarquía castellana que decide recuperar una parte del poder que tiene la iglesia con una serie de decisiones claramente laicas: la introducción del derecho romano, la creación de universidades, y hasta la adopción del romance como vehículo de la expresión culta ${ }^{22}$; si el romance adquiere fuerza frente al latín en la exposición de la historia alfonsí, ello se justifica menos como un interés por la divulgación o como consecuencia de un intento de intersección entre - permítaseme emplear un sintagma clásico, desposeyéndolo de cualquier connotación negativa - moros, cristianos y judíos.

Que los tres grupos sociales participen en la labor historiográfica del Rey Sabio no es una prueba de conciliación, sino de búsqueda de más fuentes, mejores y más refinadas que las de los equipos con que podían contar un canónigo como Lucas de Tuy o un arzobispo como Jiménez de Rada. El vehículo de expresión romance viene acompañado de un halo de modernidad, propio de una cultura más laica, en la que se basa el rey para justificar su labor política, dependiendo un poco menos de la iglesia. Con lo que la primera gran quiebra del latín en la Edad Media, dando paso al romance para la expresión formal, tiene, a mi juicio, una causa negativa: la condición del latín de vehículo de comunicación de la iglesia, de la que el poder real - como de otros poderes - trata de independizarse.

La sustitución del latín por el romance no suponía, por otra parte, una quiebra total en el uso lingüístico, pues ese latín medieval con que el Tudense defendía, con la pasión que los perdedores suelen poner en sus empresas, la preeminencia de León, era, en cierta medida, un registro formal del romance ${ }^{23}$. De ahí que a través de esta lengua de cultura aflore a cada paso la lengua vulgar ${ }^{24}$.

En dos pasajes muy próximos se refiere la crónica al calzado que se utilizaba para poder andar por la nieve a través de las montañas y que

22. M. PESET y J. GUTTIÉREZ CUADRADO, « Clérigos y juristas en la Edad Media castellano-leonesa », Vigo: Colegio Universitario de Vigo, Anejo II de Senara, 3, 1981, p. 77-110. 23. R. WRIGHT, Latín tardío y romance temprano en España y la Francia carolingia, Madrid: Gredos, 1982.

24. Como en el caso de la Historia Roderici, cf. E. FALQUE, « El romance que aflora en el latín de la Historia Roderici », in : Carlos ALVAR, Fernando GÓMEZ REDONDO y Georges MARTIN, Configuraciones políticas de la materia cidiana: realeza, nobleza e iglesia en los avatares del Cid (en prensa). 
Sancho I de Navarra hace que usen sus soldados para atravesar los Pirineos por el paso de Roncesvalles. En el primer caso explícitamente se aclara que los lugareños llaman así a este tipo de calzado:

... fecit sibi et suis militibus de coriis crudis et ligneis uiminibus rusticorum more calciamenta, que uulgariter incole « auarcas » et « baraliones » uocant, et nocte Alpes Roscideuallis per niues transiit... (p. 90)

Un poco más adelante vuelven a aparecer los dos términos juntos en el reinado de su nieto, el rey Sancho Garcés II de Navarra, quien también recibió el sobrenombre de Abarca como su abuelo:

... sicut auus eius, per « auarcas » et « baraliones » super eandem urbem Pampilonam multa milia Sarracenorum prostrauit, quare etiam ipse rex Auarca dictus fuit... (Mariana: p. 91)

El término auarca es el origen del sobrenombre Abarca que llevó en primer lugar Sancho I, rey de Navarra. La explicación - que no es la única - hace referencia a que en una de sus expediciones militares, como hemos visto, hizo calzar a sus soldados con abarcas para que caminaran mejor por la nieve. Se trata de un término común a los tres romances hispánicos, de origen desconocido, seguramente prerromano, que se extiende también por el vasco; aunque no sabemos si la forma que aparece en vasco procede del castellano o al revés, pues no hay unanimidad entre los filólogos respecto a este punto; posiblemente la forma vasca y la romance procedan de un común étimo prerromano ${ }^{25}$. En cualquier caso no es palabra latina, sino romance en el siglo XII y extendido por toda la península desde el siglo XIII.

En ambos pasajes se documentan por primera vez el término baraliones («barajones »), que debe ser el texto a que se refiere el $D E C H$, al situar esta voz « en bajo latín español, 1236 », pues es ésta la fecha de la conquista de Córdoba, el último de los acontecimientos narrados por Lucas de Tuy.

Por último, hay un ejemplo que aparece en el Chronicon mundi en el que de entre el latín de la crónica aflora el término romance balsas:

... rex Fernandus fecit fieri balsas et nauigia de lignis et coriis et ipse rex cum paucis primus transiuit. (Mariana: p. 116)

Esta voz, balsas está documentada por primera vez en castellano, según el DECH, a finales del siglo XIII en la General Estoria de Alfonso X. Nuestro texto adelantaría, pues, la documentación del término hacia 1240 aproximadamente.

25. J. COROMINAS y J. A. PASCUAL, Diccionario crítico etimológico castellano e hispánico, Madrid, 1980-1981, s.u. «abarca ». 
En otro pasaje que ha llamado la atención de algunos filólogos ${ }^{26}$, se incluye toda una frase en castellano que se traduce a continuación al latín. Cuenta nuestra crónica que el mismo día que Almanzor era vencido en Calatañazor, un pescador a la orilla del Guadalquivir llorando gritaba, unas veces en árabe y otras en castellano, una cancioncilla, que el Tudense recoge:

... quasi plangens modo Caldayco sermone, modo yspanico clamabat dicens: « En Canatanazor perdio Almazor el tambor », id est, in Canatanazor perdidit Almazor timpanum suum siue sistrum, hoc est, leticiam suam.

(Mariana: p. 88, 23-25)

Cuando se le acercaban los cordobeses, se desvanecía y volvía a aparecer en otro sitio y repetía llorando lo mismo. Sobre la identidad de este pescador no le cabe duda a don Lucas: " creemos que éste era un diablo que lloraba por la derrota de los sarracenos ».

No debe sorprendernos que este estribillo no le pasara desapercibido a Menéndez Pidal ${ }^{27}$, tan interesado por la transmision de la poesía popular en las fuentes escritas, que supuso que se trataba del estribillo de un canto de victoria de soldados, de los de cualquiera de los ejércitos castellanos que a raíz de la muerte de Almanzor habían intervenido en los asuntos de Córdoba o de otros posteriores que recordaban la muerte del caudillo musulmán.

Entre el latín y el romance, Lucas de Tuy es un eslabón que el propio Rey Sabio sabe aprovechar. Cuando en la Crónica general da entrada a balsas y avarcas tomadas de la obra de Lucas de Tuy, del mismo modo que aleve o bauzador las recoge de la Historia Roderici, está mostrando de qué modo el paso de una a otra lengua había sido propiciado por personas como el Tudense.

\section{Captatio benevolentiae en forma de GOlofón}

Pero vamos a dejar aquí este recorrido que empieza en el latín y conduce al romance, para no incumplir del todo las normas de la retórica clásica, pues, según ellas, el orador debería ganarse la benevolencia de los oyentes incluyendo al principio de su intervención una captatio benevolentiae y yo, en mi caso, voy a hacerlo al final. Aunque lo hago bien

26. Además de Ramón Menéndez Pidal, el último Juan Gil en el capítulo dedicado a Lucas de Tuy en su estudio sobre historiografía hispana, véase Juan GIL, " La historiografía », in: La cultura del románico. Siglos XI al XIII. Letras. Religiosidad. Artes. Ciencia y vida, Madrid, 1995, p. 1-109, p. 94.

27. Ramón MENÉNDEZ PIDAL, « La primitiva poesía lírica española », in: Estudios literarios, Madrid, 1957 (8 ${ }^{\mathrm{a}}$ ed.), p. 197-269, en concreto p. 232 (« En Cañatañazor/ perdió Almanzor/ ell atamor »). 
acompañada: del padre Mariana, - citado por Cirot - quien, refiriéndose a su edición del Chronicon mundi, decía que había hecho lo que había podido. Yo quisiera hacer mías esas mismas palabras, pues efectivamente he hecho lo que en mi mano, como filóloga, estaba: hacer más accesible una de las obras de aquel cronista, hagiógrafo y teólogo del siglo XIII, que nos ha reunido hoy aquí - gracias a la iniciativa de Patrick Henriet - siete siglos más tarde: Lucas de Tuy.

Emma FALQUE Universidad de Sevilla GDR 2378 - SIREM 